\title{
Tecnologias da comunicação para a cidade educativa
}

\section{Educar numa cidade-estado}

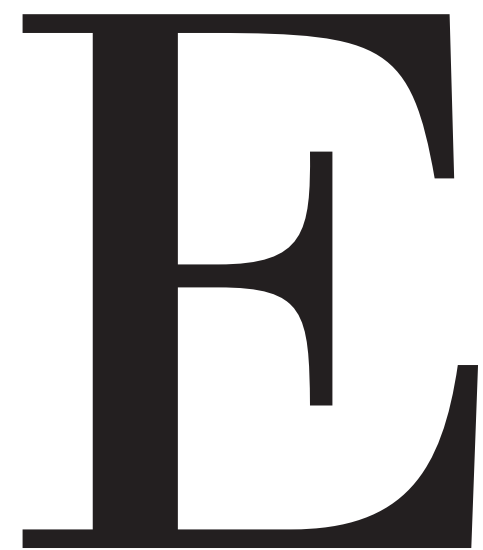

ste artigo tem origem na experiência pessoal de um pesquisador e professor universitário que dirigiu, como Secretário Municipal da Educação da cidade de São Paulo, as 1.300 escolas e seus mais de 60 mil funcionários. Minha ação, em quase 15 meses de trabalho (dezembro/ 2000 a fevereiro/2002), abrangia desde o planejamento, a execução orçamentária, o projeto de formação dos educadores (incluindo desde o faxineiro ou zelador até os professores e diretores), a manutenção e ampliação da merenda escolar (com 1,5 milhão de refeições diárias) até a compra de 14 mil computadores e a manutenção dos 1.300 prédios escolares...

0 atendimento da rede municipal de São Paulo inclui as escolas de Educação Infantil e Creches, assim como quase 600 escolas de Educação Fundamental, além de oito escolas de Ensino Médio, escolas de Educação Especial para surdos e cegos e as atividades no âmbito da Educação de Jovens e Adultos (EJA) - curso de complementação dos estudos para adultos, em períodos mais curtos, reconhecidos pelo Estado - em regime de "suplência”.

Entretanto, essa grandeza de números e essa multiplicidade de problemas são ampliadas pela inserção dessa imensa rede escolar numa complexa rede urbana, com características especialmente adversas: a cidadeestado de São Paulo.

\footnotetext{
* Fernando José de Almeida é mestre e doutor em Educação pela PUC-SP; professor do curso de pós-graduação da Faculdade de Educação da PUC-SP; foi secretário de Educação da Prefeitura de São Paulo.
} 


\section{Homenagem a uma metrópole}

São Paulo "terra da garoa". Esta era uma forma carinhosa com que se cognominava a cidade. A garoa se foi e se foi com ela também um certo carinho com que seus habitantes se dirigiam à cidade cinzenta. Foi-se a garoa, foi-se parte do carinho pela cidade. Hoje, megalópolis, ela é mais conhecida por sua violência, pela "enormidão" de seu espaço, pelo asfalto decepando as árvores, pelas massas famintas ocupando agilmente as esquinas, pelos carros que atropelam, pelas crianças pedintes nas ruas...

Cabe aqui, neste breve artigo, retomar o caráter de metrópole desta terra. Mas não como qualquer mãe, e sim como aquela à qual se colocam sempre novos problemas. E como ela responde a tais exigências! As exigências em relação às tecnologias da informação e da comunicação, de que trata este artigo, são as exigências das escolas públicas e da sociedade que as ladeia.

Cidade-mãe: metro-pólis. Ela continua sendo nossa mãe e mãe para muitos que acorrem a ela, e são centenas de milhares a cada ano, buscando suas promessas e riquezas. Riqueza que existe e é mal distribuída. Os sonhos não são dela, mas daqueles que aqui aportam ou aterrissam.

Ela é mãe e continua "mater, méter, metros-pólis"... 0 que São Paulo não perdeu foi seu caráter de abrigar as pessoas. E pode ir adiante nesta tarefa.

0 que fazem os governos e os programas democráticos da nossa República? Organizam as ações do Estado para que haja escolas, hospitais, eletricidade, água potável e esgotos, transporte, habitação e lazer...

Na função de abrigar, está o compromisso de educar.

A cidade, além de tudo, tem caráter educador. Cada vez mais os grandes centros urbanos se tornam agentes educadores, pois contêm enormes depósitos de cultura, saber, conhecimentos, técnicas, jogos de relações, espaços de convívio, obras de artes em espaços públicos, locais de trabalho, instituições educativas que em muito extrapolam o que faz a escola...

A cidade está aí, mas nem sempre a vemos em sua dimensão humanizante. Ítalo Calvino, em seu livro Marcovaldo ou as estações na cidade, conta a história fantasiosa de um personagem que vem do campo e descobre a cidade, extraindo dela muitas razões para existir.

"Esse Marcolvaldo, tinha um olho pouco adequado para a vida da cidade: avisos, semáforos, vitrines, letreiros luminosos, cartazes, por mais estudados que fos- sem para atrair a atenção, jamais detinham seu olhar, que parecia perder-se nas areias do deserto. Já uma folha amarelecida num ramo, uma pena que se deixasse prender numa telha, não lhe escapavam nunca: não havia mosca no dorso de um cavalo, buraco de cupim numa mesa, casca de figo se desfazendo na calçada que Marcovaldo não observasse e comentasse, descobrindo as mudanças da estação, seus desejos mais íntimos e as misérias de sua existência" (Calvino: 1997, p. 7).

Esta cidade é, ao mesmo tempo, mãe e madrasta. Mas é preciso, como Marcovaldo, saber olhar para ela e apelar para as suas habilidades de mãe e educadora. 0 diálogo com as múltiplas faces, sob as quais se apresenta a cidade e seus recônditos, é uma forma inteligente e responsável de se sobreviver nela e ir além.

Jornais, folhetos, faixas, cartazes em postes, pipas nos fios dos postes, paróquias e muros mostram semanalmente quantas atividades culturais, de lazer e de esportes estão disponíveis gratuitamente. É verdade que os campos de futebol de várzea minguam, comprados por empreendimentos comerciais e para asfaltamento, sem contar os preços dos terrenos. Além disso, há as ocupações "grileiras", que reduzem, a cada dia, as opções de lazer e convívio. O Estado tem se mostrado padrasto na criação das áreas públicas de lazer e cultura.

Nada de cadeiras na calçada, como nas cidades do interior do país.

As zonas Leste e Sul da cidade são as mais marcadas por essa omissão do Estado. A face criativa, educativa e artística do caldo de cultura de São Paulo está escondida pelas limitações e desconsiderações dos investimentos que nos solicitam a pensar em longo prazo, assim como o exigem os frutos da cultura e da educação.

A cidade torna-se, portanto, um currículo vivo, o lugar de onde a escola absorve seus conteúdos, sua problemática e sua polissemia. Por outro lado, a cidade mantém uma simbiose com a escola, porque por ela passam as críticas e as soluções de seus problemas, uma vez que nela estudam as gerações que comporão a direção da sociedade.

É essa concepção de currículo que exige uma leitura do mundo - a cidade é o mundo em que as pessoas entram quase sem retorno - como queria Paulo Freire. 0 fato de a escola ter um projeto educativo para a cidade, do qual ela participa não como invólucro, mas como mediadora, é um ato político. $\mathrm{O}$ ato pedagógico é um ato político forte e freqüentemente escondido. Diz Paulo Freire: 


\section{A cidade é o mundo}

\section{em que as pessoas}

\author{
entram quase sem \\ retorno, como queria \\ Paulo Freire.
}

“...quando discuto, enquanto educador, com um grupo de jovens, estou na ótica do pedagógico, pretendo convencer. Muito bem, mas convencer para quê? Para que este convencimento acrescente algo à luta pela busca de vitória de uma perspectiva de sociedade, aquela que me move... mas contribuir com este convencimento para que eles engrossem amanhã a luta pelo vencer, no sentido de mudar a história. Sou também político, portanto, e sou político na própria especificidade da pedagogia." (Freire et al.: 1985, p. 31)

Mas é fundamental que se compreendam as maquinações das organizações, das economias acumulativas e dominadoras para que se possa exercer uma prática pedagógica politicamente consistente.

Os conceitos que a pedagogia trabalhava, até o fim do século XX, não são mais suficientes para explicar as contradições pelas quais a nossa sociedade passa. Quais são os novos desafios da educação na construção de uma sociedade mais justa?

Os conceitos usuais das tecnologias na educação também não são mais adequados para compreender o que pode vir a ser a informática, por exemplo, aplicada à educação com projeto pedagógico consistente.

Já superamos a visão ingênua de que o uso do computador serve para facilitar o estudo dos jovens ou que sua finalidade é a auto-aprendizagem. Ao contrário, as novas modalidades de aprendizagem colocam novos e maiores desafios aos jovens estudantes. Nada de baratear ou infantilizar a tarefa de estudar, pesquisar e produzir conhecimento! O desafio é maior ainda: proporcionar uma educação inclusiva e de qualidade. Mas como fazer isso? Primeiro, cabe-nos esclarecer o novo conceito de exclusão.

\section{Do conceito de exploração do trabalho para a vivência da exclusão. Ou a inclusão pela cultura.}

A teoria marxista tem como um dos pressupostos para a análise do modo de produção capitalista a explo- ração do trabalho. A extração da mais-valia é hoje quase uma "delicada" forma de exploração frente à nova forma de serem tratados os desempregados na sociedade capitalista de máxima organicidade e máximos resultados. 0 que se faz em nível local e mundial é a violenta exclusão da própria sociedade, como uma espécie de morte em vida. Por ela, impede-se o acesso aos bens mínimos e se dizimam as populações não cidadãs numa sociedade em que só têm cidadania aqueles que consomem. Consumo e cidadania se identificam e se atraem.

Os números mundiais de exclusão são cada vez mais ameaçadores para as populações e para os cidadãos comuns que a sentem na pele, por meio da fome e da falta de condições na saúde, ou são suas vítimas indiretas, sofrendo com a violência das guerras e das lutas intestinas dos grandes aglomerados urbanos de países "sub".

Nosso trabalho de educadores se desenvolve e se desenvolverá nesse cenário em que a luta não é contra a exploração do trabalho, mas, mais profundamente ainda, contra a exclusão social e humana, face mais moderna e mais cruel do modelo econômico hegemônico em que vivemos, neste começo de século XXI.

Faremos, neste início, uma análise negativa do quadro social e educativo para posterior síntese propositiva.

As cidades se partem, seja por sua capacidade celular de sobrevivência, seja pela indução de políticas estatais e governamentais de subsidiar a auto-sustentação, em nichos locais, evitando assim uma espécie de "contaminação" popular em todas as áreas da urbs.

Por que se trazem aqui tais considerações?

Porque parece adequado que a forma de inclusão digital (e suas práticas correspondentes), defendida neste trabalho, seja feita segundo essa micropolítica de aproveitamento das forças que já se instalaram na sociedade.

Os aspectos educacionais, embutidos em nossa periferia e em seus sobreviventes, estão postos de maneira rude, mas clara. Os grupos se reúnem em torno de pequenas tarefas, de associações e do apoio a movimentos políticos ou religiosos cada vez mais "territorializados”. As ONGs começam a desempenhar função organizadora por "decalque" das forças vivas dos quarteirões, dos conjuntos, das quadras, dos grupos de comércio local, dos jovens etc.

Só na favela de Paraisópolis, em São Paulo, há mais de 70 movimentos sociais organizados e com forte atuação na solução dos problemas do bairro. Políticos, igrejas, organizações religiosas, de saúde, escolas e as próprias 
Administrações Regionais da Prefeitura quase nada podem fazer se não contarem com essas competências, lideranças e conhecimentos locais.

\section{0 drama}

Hoje existem em torno de $\mathbf{4 0 0}$ mil jovens e adultos analfabetos da cidade de São Paulo. De que eles sofrem?

Eles não têm acesso aos itinerários dos ônibus, às bulas de remédio, aos letreiros de filmes na TV, às contas de luz, à leitura da Constituição, aos direitos do cidadão ou do consumidor, à plataforma de seu partido político ou aos dados de seu contracheque... Seus netos, irmãos mais novos, amigos, filhos ou os transeuntes precisam ler para eles. Excluídos de uma conquista da humanidade que data de 10 mil anos, a escrita, ainda guardam na sua "poupança negativa" mais uma nova forma de exclusão: o analfabetismo nas novas tecnologias da comunicação, uma nova forma de escrita do mundo!

Para eles, esta cidade não tem o sentido que poderia e deveria de fato ter. Lêem-na, mas não a escrevem.

\section{Passo básico para o início da conversa: inclusão digital.}

A inclusão digital - conceito, repito, que deve ser alargado para além de disponibilizar máquinas e acesso à rede mundial - e a superação da exclusão digital ne- cessitam da articulação das forças vivas da sociedade, seja para absorvê-las, seja para juntas criarem inovações, atendendo a seus projetos políticos e culturais.

Passa-se por alguns questionamentos quando se trabalha com a inclusão digital em regiões carentes: estaríamos, nós, educadores, criando mais uma necessidade de consumo, trabalhando a favor dos produtores de máquinas e softwares? Será que estamos apenas mostrando da maneira mais cruel algo que eles nunca poderão ter? E mesmo que alguns escapem desse mundo marginal por dominarem alguns instrumentais da tecnologia, não estaremos oferecendo solução para a vida de apenas alguns deles, que serão exceções que confirmarão a regra da exclusão?

Milton Santos diz algo que ajuda a equacionar nossas dúvidas:

"É necessário abrirmo-nos a outras soluções fundadas no tripé: Território, Cotidiano, Culturas. Gente junta, que cria trabalho, gente reunida é produtora de economia, criando, conjuntamente, economia e cultura. E sendo produtor de cultura (diria eu, também educação) é também produtora de política. 0 país de 'baixo' é uma fábrica de manifestações genuínas, repetitivas e autênticas. É aí que se encontra a riqueza da improvisação. Essas formas espontâneas, ou quase, tanto são alimentadas pelas tradições quanto pelas inovações. Esse mundo dos homens lentos é que lhes permite fruir, gozar, ampliar a cultura territorializada, onde se dá a fusão entre o tempo




e lugar como expressão da vida em comunhão, na solidariedade e na emoção." (Santos, M.: 2000, p. 37).

Nossos grupos de pesquisadores e de formadores/ docentes têm sentido e se "pré-ocupado" com o que de fato as pessoas farão. São milhares de jovens e adultos, que se alfabetizam concomitantemente nos dois mundos - o das letras e da informática -, mas terão eles um projeto humanizador e inclusivo para a solução de seus problemas sociais? $\mathrm{Ou}$, antes, poderão cair nas facilidades de sempre se sentirem inferiores e nunca suficientemente dominadores do instrumental para uma verdadeira interferência na solução dos problemas locais. E, se eles se descuidarem, terão a maior parte de seu tempo tomado para dominar os malabarismos com a máquina e pouco tempo para investigar as possibilidades que a máquina oferece no sentido de equacionar seus mais elementares problemas.

De novo, Milton Santos (2000, p. 36) aponta uma perspectiva:

"Esse cotidiano que é a quinta dimensão do espaço, reúne as heranças, o presente fugaz e o futuro sonhado, permitindo que o pragmatismo da vida cotidiana, lembrado por Agnes Heller, ${ }^{1}$ acabe sendo um pragmatismo existencial, movido pela emoção. Esse cotidiano aparece de um lado como coerência do grupo com seu entorno, como o meio, como o lugar, produzindo manifestações que, por essas raízes, são dotadas de força e, de outro, permite a produção da transgressão, isto é, a capacidade de não aceitar o estabelecido, tanto na idéia quanto na prática. Aliás, essa é a única forma de produzir o futuro."

Embora o texto de Milton Santos se refira ao lazer, sua aplicação à educação e à inclusão digital nas camadas populares é plenamente adequada. A instrumentalização desses grupos sociais para o uso dessas tecnologias começará a fazer parte de seu arsenal de leitura e lutas.

\section{Sobre nossos alunos Jovens e AdULtos QUe PARTICIPAM DO ALFA-DIGITAL ${ }^{2}$}

As nossas pesquisas nos mostram, neste ano e meio de trabalho de pesquisa na PUC-SP (de abril de $2001 \mathrm{a}$ dezembro de 2002), que a primeira arma que os alunos adquirem com o acesso à tecnologia é a auto-estima. Os testemunhos são inúmeros e, com a estima recuperada (mesmo que em parte, pois o problema é muito maior), as conquistas foram: a maior disposição para virem às aulas, falarem mais, ouvirem melhor, falarem de si e com os outros, trazerem suas famílias simbolicamente e as ricas histórias de seus nomes e de vida. Trata-se daquilo que Silva (2003: p. 48) chama de autobiografia educativa.

"Assim, uma pesquisa sobre a formação de adultos que resistem à alfabetização a partir da perspectiva autobiográfica pode ter esse efeito terapêutico. Ou seja, há efeitos de narcisação da pessoa, pois quem antes se acreditava incapaz pode descobrir as suas reais capacidades, substituindo uma antiga identidade do ser incapaz pela identidade de ser capaz. Portanto, a autobiografia educativa pode se tornar um excelente instrumento para atravessar o pior."

Os trabalhos de investigação que estão sendo desenvolvidos por oito mestrandos e doutorandos da PUC-SP sobre o ALFA-digital deverão se debruçar sobre os resultados, metodologias, êxitos, dificuldades e olhares teóricos sobre o seu desenvolvimento, que hoje é nosso projeto de ponta para a análise de prática de ações inclusivas na área digital.

Esse projeto complementa de modo estrutural as propostas feitas por muitas ONGs ou governos municipais, estaduais ou mesmo federal. No entanto, é importante esclarecer que o conceito de inclusão digital tem sido muito mal entendido e ainda falta muito para entendê-lo e para configurá-lo de maneira teoricamente sólida. Em geral, para a inclusão ou alfabetização basta - principalmente para os oportunistas que visam sobretudo ao alargamento do mercado - ter domínio dos segredos dos teclados, do manuseio dos programas ou da lógica de funcionamento das máquinas, como a aprendizagem de programação.

Um dos estudos mais clarividentes sobre esse tema encontra-se no livro Letramento no Brasil, de Vera Masagão.

\section{A construção de uma diferente visão de alfabetização digital. Uma antevisão.}

Quais são as principais questões que o conceito de alfabetização apresenta a um novo conceito de mundo?

0 mundo mudou. 0 conceito de alfabetização mudou. A leitura deste mundo não pode ser feita com os mesmos instrumentos e códigos de mundos passados.

No mundo da agricultura - com seu conceito de tempo, sua ligação íntima com a terra, com os fluxos das estações e o ritmo dos plantios, com seu modo de trabalhar, com o efeito de suas chuvas, das messes, das imprevisões - os instrumentos gerados para sua leitura 
eram bem específicos. Os deuses ofereciam algumas explicações para as leituras. As artes ofereciam outras. As famílias e suas organizações, outras ainda. Os códigos de comunicação foram criados para dar conta de explicar tal mundo e suas exigências concretas.

Hoje, vivemos em um mundo fortemente marcado pela informação e seu tráfego. É nele que encontramos nosso trabalho. 0 mundo digital encurta distâncias, reduz espaços, acumula dados, transporta imagens e sons à velocidade da luz, vive muito de imagens e fala menos a palavra oral. A tela é o cenário, e as cores, aos milhões, são seus atores fluidos e plásticos. Aquilo que pode vir-a-ser é mais cultivado do que aquilo que de fato é. A virtualidade da imagem e das relações quase substitui a realidade. Jogar xadrez com a máquina pode ser mais valorizado que jogar com um parceiro. 0 enxugamento dos postos de trabalho é o seu avatar. A racionalidade pura, as emoções icônicas, plastificadas e substitutivas são seu destino.

Quais são os instrumentos de leitura deste novo mundo?

Paulo Freire dizia que ler é tomar consciência. A leitura é, antes de tudo, uma interpretação do mundo em que se vive. Mas não é só a leitura que permite essa interpretação. É necessário também representá-lo pela linguagem escrita, falar sobre ele, interpretá-lo, escrevê-lo. Ler e escrever, dentro dessa perspectiva, é libertar-se - leitura e escrita como prática de liberdade.

Quais são os nossos instrumentos de leitura deste mundo, que atualmente é outro e tem na informática e nas novas tecnologias da comunicação novos modos de produção de vida, de relação de trabalho e de poder?

Quais são os temas que dele emergem e que nos permitem escrever este mundo?

0 que tenho que aprender para saber lê-lo? Como problematizá-lo? Quais são seus códigos? Como dominá-los para a comunicação? Quais os problemas que traz dentro de si? Quais são os átomos de conhecimento que devemos dominar para termos uma alfabetização dentro da perspectiva freiriana?3

De que digitalidade estamos falando?

Da digitalidade cidadã que se opõe ao digital servil, inocentemente maravilhado e docemente ingênuo. 0 mundo das novas tecnologias da informação não se apresenta aos seus usuários docilmente, como se fosse um éden de facilidades e de libertação das tarefas repetitivas e rotineiras do ser humano. Essas novas tecnologias fazem
Quais são os nossos

instrumentos de leitura

deste mundo, que atualmente

é outro e tem na informática e

nas novas tecnologias da

comunicação novos modos

de produção de vida, de relação de trabalho e de poder?

parte de um mundo que deve ser conquistado por ações tecnológicas, educativas e políticas. No fundo, o mundo das informações e do conhecimento são espaços de lutas. Suas apropriações se dão por esforços organizados, intencionalmente construídos em planejamentos estratégicos sofisticados.

\section{Conceitos se completam com métodos}

Diferentes grupos de trabalho, na PUC-SP e alguns, fora dela, realizaram a construção de um método que nasceu da prática com alunos, professores do ALFAdigital e pesquisadores e docentes da universidade. O método foi construído a partir da vivência de cada um destes segmentos. Como se operaram essas vivências?

A primeira consideração é que nada seria repassado para os alunos. As atividades, reflexões e aprendizagens seriam experimentadas por todos os elementos dos grupos.

- Cada um fala da própria experiência de exclusão digital e como se incluiu (ou porque pretende entrar) nesse mundo: medos, desejos, imaginários, sonhos, expectativas. Isto iguala a todos no que se refere a entrar em novos mundos cheios de promessas e restrições, senhas, subsenhas e enigmas.

A fala é o primeiro caminho da inclusão. A oralização é prévia e estruturadora do conhecimento. Vivê-la, principalmente em grupo, e partilhá-la é o início do processo de apropriação do mundo, seja ele digital ou não. Essas experiências foram feitas pelos docentes da PUC-SP, mestrandos, professores da rede e alunos do ALFA-digital.

- Registramos todas as evoluções do trabalho. Os arquivos do computador nos permitem, com mais facilidade, registrar a evolução do que a turma produziu, suas falas, dificuldades, o material que foi 
Mas as tecnologias não nasceram com o destino de democratizar o saber, distribuir cultura ou "rearrumar" democraticamente a economia.

\section{O ALFA-digital começa a trilhar este caminho?}

\section{Dentro desta ótica realista, mas esperançosa - de que} a tecnologia não é obra de um destino demoníaco, mas fruto da história - foi levado adiante o projeto ALFA-digital.

Sua perspectiva girou em torno de um projeto de ocupação estratégica de espaços em que as classes sociais e seus subgrupos se organizam.

É dentro dessa perspectiva política que o ALFA-digital se apresenta. Ou seja, como parte de uma estratégia de governo, articulada com o projeto do Governo Eletrônico
- coordenado, em 2001 e 2002, por Sérgio Amadeu Silveira - para criar mais espaços democráticos para uma gestão da cidade e da vida dos cidadãos de São Paulo. 0 Orçamento Participativo, o acompanhamento da gestão dos governantes, do andamento dos projetos na Câmara e o acompanhamento da execução orçamentária são exemplos da viabilização da democracia por meios digitais.

Gestão democrática só se dá com tecnologias de gestão, sejam elas tecnologias da consciência ou constituídas por recursos físicos. É a partir dessa ótica que se construiu o Plano conceitual e metodológico do ALFA-digital.

Trata-se de um primeiro projeto indicativo para que os vários setores organizados da educação, ligados à área de alfabetização de jovens e adultos, discutam, proponham, reorganizem e construam diretrizes e programas lido, os disquetes das produções individuais, desde os primeiros contatos com o micro e suas discussões preparatórias.

Nesse sentido, é importante frisar que quase nenhuma atividade foi levada para o dia de trabalho na máquina sem que tivesse, de alguma forma, sido antes discutida em sala. As atividades mais corriqueiras e mobilizadoras eram tratadas diante da máquina, ou o que se fazia em sala: a história do próprio nome, sua terra de origem, as famílias, as tradições culturais, as receitas, as histórias, as profissões atuais, os sonhos, ou os temas por eles escolhidos, como as eleições (como votar em urna eletrônica) e o que isso significa, o debate sobre a ALCA...

- Outro procedimento metodológico importante era saber trabalhar com o erro, usá-lo como instrumento para a apropriação do saber. A aceitação do erro é uma tarefa difícil, seja para os alunos, seja para nós, professores. Mas sobretudo para os alunos, pois suas experiências, quando flagrados em erro, foram muito negativas.

De um lado, porque acreditam que, por serem adultos, não podem errar em coisa que as crianças lidam com tanta desenvoltura. De outro, porque o erro é tratado como descaso, desmazelo, burrice ou inferioridade... pelos professores. Por isso, o computador Ihes trouxe uma grande contribuição, pois, aliado à nossa metodologia, não punia nem denunciava o erro. Eles gostam do computador porque sai tudo "certinho e organizado", evitando aquele aspecto de gar ranchos e de confusão na organização das folhas de caderno.

De outro lado, sentiram-se favorecidos, pois, ao apagar os erros, nada ficava registrado (ao contrário das marcas que a velha borracha deixava nas folhas amassadas e manchadas). Além disso, 0 computador faz aparecer a "cobrinha vermelha", denunciando que a palavra não está correta.

Os professores disseram para eles que a "cobrinha" não indica necessariamente erro, mas que o computador não conhece aquela palavra. Eles ficaram muito aliviados e chegaram a revidar, dizendo, orgulhosos: "Então sabemos mais palavras do que ele!". O tratamento do erro é outro procedimento que é vital para este tipo de trabalho.

- Troca contínua das produções entre a classe.

- Leitura e escrita como tomada de consciência do mundo. No entanto, esta consciência crítica começa pela emoção: estou sendo privilegiado, vejo logo o que escrevo, posso levar para casa, tenho acesso ao mais moderno ícone da participação social - o computador.

- Comemorava-se a síntese de cada grande unidade com festividade e a publicação do que se fez. Dar valor, assim como valorização e avaliação - todas têm a mesma raiz etimológica - foi um dos cernes da avaliação realizada. 
para a apropriação democrática de mais um constructo tecnológico que historicamente deve ser humanizado: as tecnologias digitais.

"Ter contato com a informação pode não gerar conhecimento", reconhece Silveira (2001, p. 5), mas também não é suficiente termos projetos e programas pedagógicos para que a inclusão se faça, sem que haja acesso à rede.

"É preciso inserir as pessoas no dilúvio informacional das redes e orientá-las sobre como obter conhecimento." (Silveira: 2001, p. 21).

O destaque na palavra "obter" diz respeito ao conceito equivocado que escapa do autor. Ele contém a idéia de que $o$ acesso gera obtenção do conhecimento quase que por contato, e omite que não basta a disponibilidade em rede, pois não se deve esquecer que o conhecimento se constrói e não apenas se veicula.

Por isso, é necessário também um processo intencional e educativo que acompanhe os procedimentos de aprendizagem significativa, mediados pela rede.

0 importante, como base dos novos projetos da chamada inclusão digital em sua fase "um", é que a socialização das redes (equipamentos, pontos de Internet e conectividade) é um direito, que alarga a cidadania e melhora as condições de vida.

Há um momento importante do livro de Silveira (2001, p. 21-22), em que ele afirma:

“...a proficiência em massa de pessoas para o uso de tecnologia da informação pode gerar a sinergia essencial para o desenvolvimento sustentado do país."

Essa parece uma posição lógica e historicamente correta de se enfrentar o problema do desemprego estrutu-

\section{Bibliografia}

ALMEIDA, F. J. Quem educa o computador? São Paulo: Editora Paulus, 2005.

BRISSAC DE SOUZA, Nelson. ARTECIDADE $n \div$ 4, São Paulo, SESC-SP, 2002.

CALVINO, Ítalo. Marcovaldo ou as estações na cidade. São Paulo: Companhia das Letras, 1997.

FREIRE, Paulo et al. Pedagogia: diálogo e conflito. São Paulo: Cortez, 1985.

GRAMSCI, Antonio. O Estado e a organização da cultura. Cia. Editora Nacional.

LE GOFF, M. Por amor às cidades. São Paulo: Unesp, 1998.

MASAGÃO, Vera (Org.). Educação de jovens e adultos. Campinas/São Paulo: Mercado de Letras/Ação Educativa, 2001.

. Letramento no Brasil. São Paulo: Global, 2003.

NIETZSCHE, F. Crepúsculo dos ídolos. Revista Margem, São Paulo, Nova Cultura, 1999.

SANTOS, M. O Lazer numa sociedade globalizada. São Paulo: SESC, 2000. ral que decorre da função precípua das novas tecnologias. A lógica precisa ser quebrada: o conhecimento gera melhoria das formas de produção, que gera novas modalidades de trabalho, que, por sua vez, é mais exigente quanto às habilidades (especialização), que provoca a diminuição de postos de trabalho e, com isto, mais acumulação... e assim por diante.

Está colocado o problema: há que se estranhar este mundo e não apenas louvá-lo, atribuindo todo o mérito a ele e o demérito para os desempregados que não o acompanham. Ele está construído para formar as crateras de desempregados e de inadaptados, que prestigiam ainda mais os que a ele conseguem se adaptar. 0 importante é que construamos uma contrapolítica da acumulação-exclusão para a distribuição-inclusão. Para tanto, será fundamental dominar não apenas a produção de hard/software, mas também os mecanismos de difusão do pensamento e da lógica informacionais.

A divulgação é conditio sine qua non, mas não suficiente... Para isso, é necessário o debate social sobre as entranhas do modelo de produção, disseminação e apropriação dos bens culturais disponíveis ou, ainda, os "produzíveis". Esse debate educacional deve ser seguido de experimentos de sondagem da cultura local, o que viabiliza a documentação, amplificação sensorial dos produtos da cultura e sua conseqüente (ou não) simbiose com a cultura "universalizante". Ele propõe romper com o conceito de inclusão visto apenas como uma inclusão mercantil. Tal ruptura pode nos levar a uma reversão da curva perversa da lógica da acumulação: quem já tem sempre terá mais.

SILVA, Nilce. Exclusão social: espaço de criação como alternativa educacional. São Paulo: I. Editora, 2003.

SILVEIRA, Sergio Amadeu da. Software livre. São Paulo: Perseu Abramo, 2004.

SESC-SP. Lazer e cultura numa sociedade globalizada. São Paulo: SESC-SP/WLRA, 2000.

\section{Notas}

1 HELLER, Agnes. O Cotidiano e a história. Rio de Janeiro: Paz e Terra, p. 37.

2 É o nome dado ao Mova Digital, depois que a Secretaria Municipal de Educação de São Paulo descontinuou o projeto. O Alfa Digital continua em algumas escolas e como linha de pesquisa e serviços do Programa de Pós-graduação em Educação, Currículo, PUC-SP.

3 Embora algumas tendências analíticas denominem de letramento este conjunto de propostas, de objetivos e de formação de habilidades, chamaremos aqui esta aproximação inicial do mundo dada pelo domínio dos códigos escritos e de algumas linguagens - de alfabetização. 